Check for updates

Cite this: RSC Adv., 2018, 8, 34275

Received 14th June 2018

Accepted 14th September 2018

DOI: 10.1039/c8ra05118f

rsc.li/rsc-advances

\section{Praseodymium-decorated graphene oxide as a corrosion inhibitor in acidic media for the magnesium AZ31 alloy}

\author{
N. Palaniappan, iD *a Ivan. S. Cole, ${ }^{\text {b }}$ F. Caballero-Briones, ${ }^{c}$ Balasubaramanian K. ${ }^{d}$ \\ and C. Lal ${ }^{\mathrm{e}}$
}

\begin{abstract}
In the present work, Pr-decorated graphene oxide was synthesized and tested as a corrosion barrier layer in acidic media for the magnesium AZ31 alloy. The morphology, composition and structure of Prdecorated graphene oxide sheets were characterized via HRTEM, FESEM, Raman, XRD, DLS, UV and FTIR studies. The corrosion inhibition efficiency on the alloy surface was monitored via microstructural and electrochemical methods. The results indicate that Pr-decorated graphene oxide provides improved protection for the Mg AZ31 alloy compared to conventional epoxy coatings. The proposed mechanism arises from a combination of the barrier activities of the composite, $\mathrm{GO}+\mathrm{Pr}$, and the epoxy coating on the Mg alloy in acidic media.
\end{abstract}

\section{Introduction}

Magnesium alloys are alternative materials for use in biomaterials, hydrogen storage, automobiles, and the airbus manufacturing industry, due to their prominent properties, such as light weight and high metallurgic strength. ${ }^{1}$ Magnesium alloy native oxide films are not stable in strongly acidic and salty environments, and accelerated corrosion occurs due to the poor stability of the native oxide layer in acidic media. As a result of this, 14 and 15 block and $\mathrm{Zn}$ elements are added to make new $\mathrm{Mg}$ alloys to improve the corrosion resistance of magnesium alloys in salty media. ${ }^{2}$ In addition, Cr nanoparticles have been used as corrosion inhibitors; however, these are carcinogenic agents, and several countries have banned Cr based coating materials. ${ }^{3}$ Other solutions for $\mathrm{Mg}$ alloy corrosion inhibition improvement involve using inhibitors, such as ammonium ions, phytic acid, amino acids, organic silicates, inorganic $\mathrm{Zn}$, anionic surfactants, and 2-hydroxy-4-methoxy-acetophenone. Further, $\mathrm{Mg}$ alloy microstructures are protected using tetraphenylporphyrin, sodium fluoride, and inorganic and organic inhibitors. ${ }^{\mathbf{4 - 1 2}}$ Hence, hydroxyapatite and $\mathrm{Ca}^{+}$cations are added to improve corrosion resistance. ${ }^{\mathbf{1 3 , 1 4}}$ Furthermore, the effects of

${ }^{a}$ Central University of Gujarat, 382030, India. E-mail: palaniappancecri@rediffmail. com

${ }^{b}$ Advance Manufacturing and Fabrication Research and Innovation, RMIT University, Melbourne, Vic 3100, Australia

'Instituto Politécnico Nacional, Materials and Technologies for Energy, Health and Environment (GESMAT), CICATA Altamira, Km 14.5 Carretera Tampico-Puerto Industrial Tamps, Mexico

${ }^{d}$ Department of Materials Engineering, Defence Institute of Advanced Technology, Girinagar, Pune 411025, India

${ }^{e}$ Harcourt Butler Technical University, Kanpur, India
$\mathrm{NaCl}$ electrolytes in the corrosion medium on $\mathrm{Mg}$ alloy dissolution in the $\mathrm{Mg}^{+}$state, and the associated microstructures have been analysed via SVET methods. ${ }^{15-19}$ In addition, $\mathrm{d}, \mathrm{s}$ and $\mathrm{f}$ block elements are used to enhance corrosion resistance in $\mathrm{NaCl}$ environments, such as zirconium, arsenic, phosphates, germanium, lutetium, neodymium, cerium, $\mathrm{La}^{3+}$, Dy and mischmetal. ${ }^{20-29}$ Further, cathodic hydrogen evolution is controlled using inhibitor molecules. ${ }^{30-32}$ Coatings have been used on magnesium surfaces as self-healing agents to increase long term protection..$^{33-35}$ Hence, rare earth chlorides, carboxylate complexes, anionic surfactants, and cerium complexes are used as green corrosion inhibitors. And large-surface areas, high electron densities and rare earth complexes can also enhance the corrosion inhibition efficiency. ${ }^{36-47}$ In recent years, functionalized graphene oxide materials have been reported, such as poly(urea-formaldehyde), tin oxide, plasma based, and epoxy + graphene composite coatings, graphene ink, covalently functionalized $\mathrm{N}$-graphene oxide, and ionic liquids, which are excellent corrosion barrier layers on alloy surfaces because they are impermeable to electrolytes and gas molecues. ${ }^{48-58}$ Furthermore, GO functional groups can also enhance electron donation and accepting from the alloy surface. ${ }^{59,60}$ The predominant properties of functional graphene oxide materials have a significant impact on overcoming corrosion failure. We have created decorated praseodymium based GO sheet materials as a low cost corrosion inhibition barrier layer. They could enhance the life span of the coating on the alloy surface, and overcome conventional epoxy coating failure. Our research aim is the facile synthesis of praseodymium-decorated graphene oxide, to study the possible corrosion inhibition effects on $\mathrm{Mg}$ alloys in acidic media, as metallurgy, automobile industry pickling, and other works take place in strong acidic media. 
Further, $\mathrm{Mg}$ alloy corrosion mitigation has not yet been achieved due to traditional epoxy coating failure. We first investigated a GO + Pr composite coating on Mg alloys as a corrosion inhibition barrier in acidic media. The novelty of the GO decorated material is the intercalation of small sized $\operatorname{Pr}^{3+}$ between the graphene oxide layers to enhance corrosion resistance; the coating lifespan increased in acidic media compared to epoxy coatings.

\section{Experimental section}

\subsection{GO synthesis}

Graphite powder, $\mathrm{H}_{2} \mathrm{SO}_{4}, \mathrm{H}_{3} \mathrm{PO}_{4}, \mathrm{H}_{2} \mathrm{O}_{2}, \mathrm{NaNO}_{3}, \mathrm{KMnO}_{4}$, and $\operatorname{Pr}\left(\mathrm{NO}_{3}\right)_{3}$ were purchased from Alfa Aesar Company and used without further purification. GO was synthesized via a modified Hummers' method. ${ }^{61}$ In brief, $1 \mathrm{~g}$ of graphite powder was placed into a $250 \mathrm{~mL}$ round bottom flask (RB), and $40 \mathrm{~mL}$ of $\mathrm{H}_{2} \mathrm{SO}_{4}$ and $60 \mathrm{~mL}$ of $\mathrm{H}_{3} \mathrm{PO}_{4}$ were slowly added. The mixture was kept in an ice bath and $3 \mathrm{~g}$ of $\mathrm{KMnO}_{4}$ and $0.1 \mathrm{~g}$ of $\mathrm{NaNO}_{3}$ were slowly added to the mixture, which was then kept under reflux at $60{ }^{\circ} \mathrm{C}$ for $12 \mathrm{~h}$. After the mixture was cooled to room temperature, it was poured into $1000 \mathrm{~mL}$ of ice water, and then $10 \mathrm{~mL}$ of $30 \% \mathrm{H}_{2} \mathrm{O}_{2}$ was added to terminate the reaction. The resultant GO was washed with plenty of deionized (DI) water until neutrality was achieved.

\subsection{GO-praseodymium decoration}

For decoration, $200 \mathrm{mg}$ of GO powder was placed into a round bottom flask containing $100 \mathrm{~mL}$ of DI water. The mixture was sonicated to finely disperse the GO using an SB-300 DTY multiultrasonic cleaner operating at $40 \mathrm{~W}$ and a frequency of $40 \mathrm{~Hz}$. After that, $100 \mathrm{mg}$ of $\operatorname{Pr}\left(\mathrm{NO}_{3}\right)_{3}$ was added into the GO solution, followed by $10 \mathrm{~mL}$ of $1 \mathrm{M} \mathrm{NaOH}$ solution as an activator. The mixture was continually stirred for $24 \mathrm{~h}$, as shown in Scheme 1.

The resulting product was washed and centrifuged at $5000 \mathrm{rpm} 5$ times to remove remaining alkali. The GO $+\mathrm{Pr}$ material was dried at $80{ }^{\circ} \mathrm{C}$ in a vacuum oven for $24 \mathrm{~h}$ and kept in a desiccator before being used as an anti-corrosion coating material (Fig. 1).

\subsection{Material characterization}

Graphite, GO and the GO-Pr material were characterized via powder X-ray diffraction with a D8 instrument from Bruker, using $\mathrm{Cu} \mathrm{K} \alpha$ radiation $(\lambda=1.5406 \AA$ ) . The optical absorption

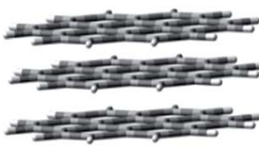

GO

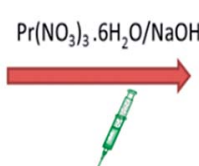

同

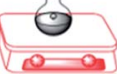

Scheme 1
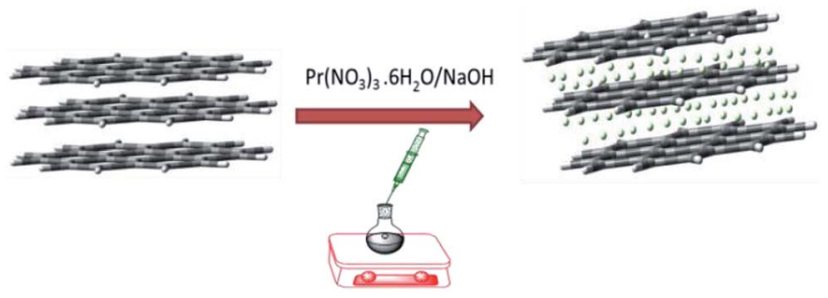

Fig. 1 Schematic illustration of the GO decoration.

was studied by finely dispersing $0.1 \mathrm{mg}$ of graphene oxide flake in DI water to make a stable, transparent dispersion, and studying this using a milli-Q A10 TOC spectrometer in the 200$600 \mathrm{~nm}$ range. The molecular structure, i.e. the functional groups, was studied using an FTIR Spectrum 65 instrument from PerkinElmer. Thermal behaviour was tested using SII TG/ DTA7300 apparatus. The microstructures of the materials were studied via confocal Raman spectroscopy, using a $532 \mathrm{~nm}$ laser as the excitation source, with a WITec Raman microscope. The morphologies and compositions of the materials were studied using a Carl Zeiss FESEM Marline compact microscope equipped with an EDX detector. The size distributions and zeta potentials of aqueous solutions were studied using a Microtrac Zetatrac U2771. Thin film analysis was conducted using Horiba UVi Cell2 apparatus over a range from 1.5000$6.0000 \mathrm{eV}$ at increments of $0.0500 \mathrm{eV}$. The GO sheet morphology and GO + Pr composite material crystallinity were observed using an FEI Techani F Twin 500 transmission electron microscope.

\subsection{Coating methods}

As shown in Fig. 2, before coating, the $\mathrm{Mg}$ alloys were polished with different grades of silicon paper, from 600 to 1200 microns. The epoxy powder was purchased from Mathura chemical Pv. Ltd. Hence the coating material, the (GO + Pr) composite, and a hardener, polyamine, were mixed in a $2: 1$ (10 $\mathrm{mg}: 5 \mathrm{mg})$ weight ratio. The mixture was finely dispersed using an SB-300 DTY multi-ultrasonic cleaner operating at $40 \mathrm{~W}$ and a frequency of $40 \mathrm{~Hz}$; the colloids were taken as the coating material. The epoxy coating material was prepared via the same method. The coating was carried out using a brush, and the brush size was $0.2 \mu \mathrm{m}$. The coated $\mathrm{Mg}$ alloy was dried before being used in corrosion inhibition studies at a temperature of $80^{\circ} \mathrm{C}$ in a hot air oven.

\subsection{Corrosion inhibition}

The magnesium AZ31 alloy samples were prepared according to the literature ref. 62 . The test $\mathrm{Mg}$ alloys were $1 \mathrm{~cm} \times 1 \mathrm{~cm}$ squares of Mg AZ31 alloy, with a $1 \mathrm{~mm}$ thickness, polished with a series of different grade silicon carbide paper, from 600 to 1200 microns. The corrosion medium was $1 \mathrm{M} \mathrm{H}_{2} \mathrm{SO}_{4}$ solution, and the GO-Pr and epoxy-coated $\mathrm{Mg}$ alloys were immersed for 3 days in the corrosion medium. The corrosion inhibition efficiency was analysed using CHI 920D electrochemical workstation software; the coated $\mathrm{Mg}$ alloy was set as the working 

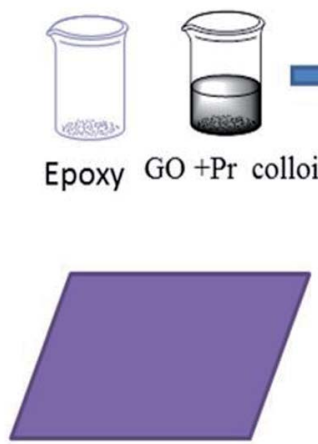

Epoxy Mg

alloys
Epoxy GO +Pr colloids
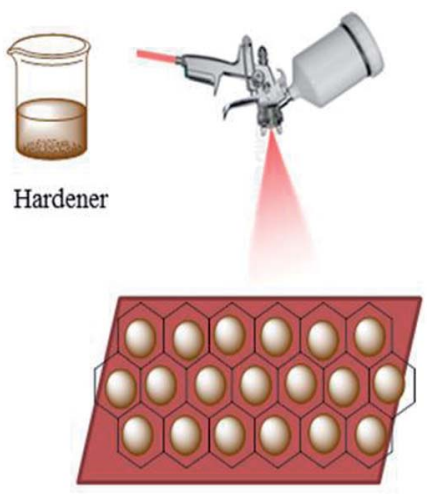

GO+Pr Coated

Mg alloys
Fig. 2 A schematic illustration of the methods for GO + Pr composite and epoxy coating.

electrode, platinum foil was the counter electrode and $\mathrm{Ag} / \mathrm{AgCl}$ (KCl Sat) was reference electrode. The electrochemical reaction was carried out with respect to an open circuit potential of \pm $250 \mathrm{mV}$ at a $0.1 \mathrm{mV}$ scan rate. The corrosion inhibition efficiency $\left(\eta_{\mathrm{IE}}\right)$, double layer capacitance $\left(C_{\mathrm{dl}}\right)$, quantum chemical calculation of electronegativity $(\chi)$, global hardness $(\eta)$, softness $(\sigma)$, and electrophilicity $(\omega)$ were calculated via the following equations:

$$
\begin{gathered}
\eta_{\mathrm{IE}}=\frac{I_{\mathrm{o}}-I_{\mathrm{i}}}{I_{\mathrm{o}}} \times 100 \\
C_{\mathrm{dl}}=\frac{1}{2 \pi f_{\max } R_{\mathrm{ct}}} \\
\eta=\frac{I-A}{2} \\
\chi=\frac{I+A}{2} \\
\sigma=\frac{1}{\eta} \\
\omega=\frac{\chi^{2}}{2 \eta}
\end{gathered}
$$

where $f_{\max }$ is the maximum frequency, $R_{\mathrm{ct}}$ is charge transfer resistance, $I_{\mathrm{o}}$ is the current density of the epoxy coating and $I_{\mathrm{i}}$ is the current density of the GO + Pr coating.

\section{Results and discussion}

\subsection{Morphology and GO and GO + Pr composition}

Graphene oxide (GO) microstructures are presented in Fig. 3. In Fig. 3A, an FESEM image of $\mathrm{GO}^{63-65}$ shows few layer graphene oxide sheets and continuing sheet form, due to oxidation. Fig. 3B and C provide HRTEM images of GO, showing few interlayers and an average sheet size of $100 \mathrm{~nm}$ to $200 \mathrm{~nm}$. Further confirmation, as shown in Fig. 3D, through selected area electron diffraction (SAED) studies of
GO indicates polycrystalline sheets and elements analysis by EDX. And the GO sheet size is analysed via Gatan microscope software; the GO nanosheet sizes are presented in Fig. 3E and a elemental mapping of GO. Further, praseodymium decorated graphene oxide (GO-Pr) FESEM images are presented in Fig. 4A and B. The Pr decorated GO sheets appear bright due to Pr nanoparticles being incorporated in the graphene oxide sheets, and in addition, a HRTEM micrograph and selected area electron diffraction (SAED) pattern of polycrystalline GO-Pr are presented in Fig. 4C. A GO nanosheet with corresponding Pr nanoparticles spread all over the GO sheets is presented in Fig. 4D. This suggests that well defined $\mathrm{Pr}$ nanoparticles are incorporated into the graphene oxide sheet. It also attributes polycrystallinity to the graphene oxide sheets.

Further, the Pr particles are analyzed using Gatan digital microscope software, and the sizes are shown in Fig. 4E. Element mapping of GO + Pr is presented in Fig. 5. It suggests that praseodymium nanoparticles interact with the graphene oxide sheets, and the $\mathrm{C}, \mathrm{O}$, and Pr elements are uniformly distributed on the graphene oxide surface. The microscopy results suggest that GO and the composite GO + Pr material have similar microstructures. The X-ray diffraction spectrum of GO powder is presented in Fig. 6A; the characteristic graphene oxide (002) reflection at $2 \theta=11.6^{\circ}$ and the graphite related (002) reflection at $2 \theta=25.7^{\circ}$ show that GO is partially reduced during the synthesis. ${ }^{66}$ However, GO with well exfoliated sheets (GO

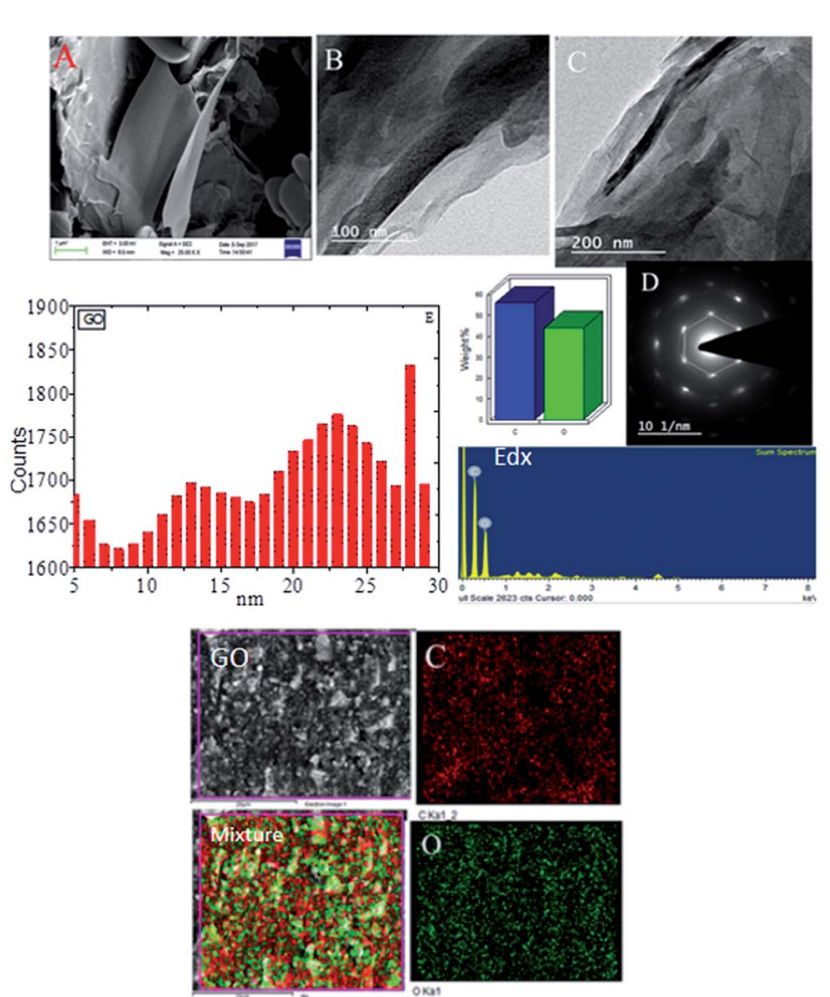

(a) Elements Mapping GO

Fig. 3 FESEM images of GO (A) and GO (B and $C)$ of HRTEM micrograph (D) SAED pattern and EDX of GO and (E) of GO nano sheet size. (a) Elemental mapping of GO. 

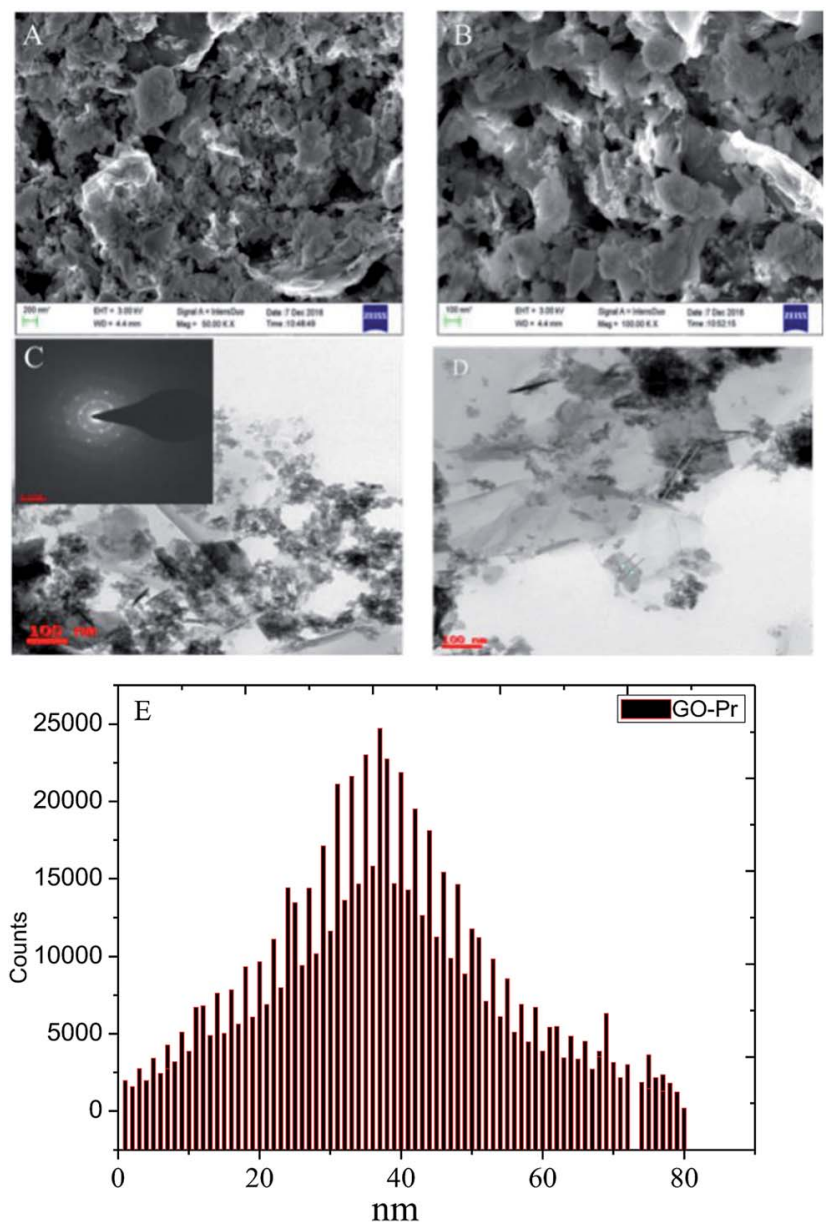

Fig. 4 FESEM images of $\mathrm{GO}+\operatorname{Pr}(\mathrm{A}$ and $\mathrm{B})$, HRTEM images of $(\mathrm{Pr}+\mathrm{GO})$ $(\mathrm{C}$ and $\mathrm{D})$, and $(\mathrm{E}) \mathrm{GO}+$ Pr particle size data.

$(002)=0.76 \mathrm{~nm})$ is attained with this preparation, as observed in the HRTEM images. A GO-Pr diffraction spectrum is presented in Fig. 6B, where several diffraction peaks assigned to elemental $\mathrm{Pr}$ (beta and hexagonal phases), $\mathrm{Pr}_{4} \mathrm{O}_{7}$ and $\mathrm{Pr}$ -
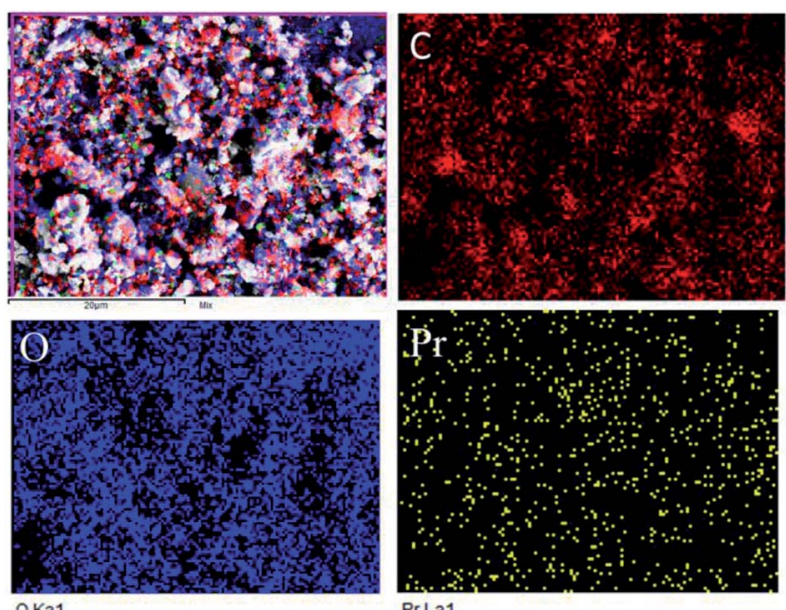

O Ka1

PrLa1

Fig. 5 Composite elemental mapping of GO + Pr.

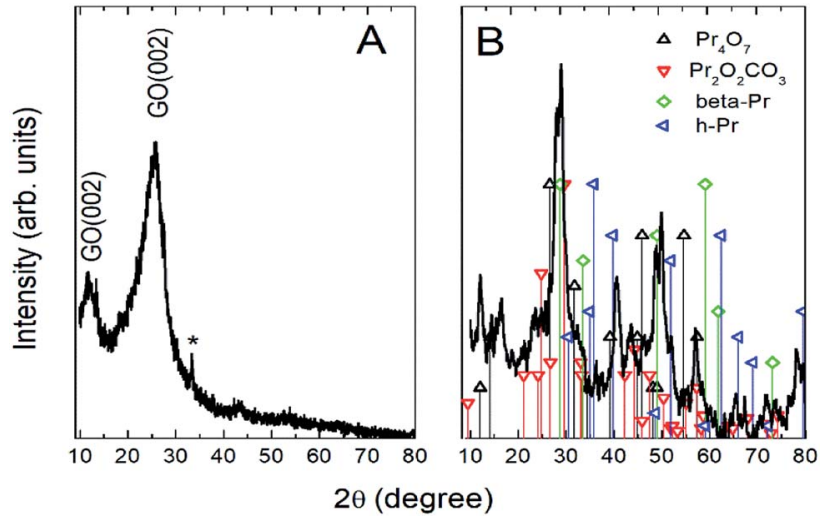

Fig. 6 XRD of $\mathrm{GO}$ and (GO + Pr) decorated GO sheet.

carbonate phases are observed, due to the effects of $1 \mathrm{M}$ $\mathrm{NaOH}$ strong basic conditions, and a possible mechanism is shown in Fig. 7 for how different phase Pr particles formed, ${ }^{67}$ which is confirmed by the SAED pattern. There are other peaks that could not be indexed, which probably correspond to Praromatic phases from Pr reactions within GO basal sheets. ${ }^{68-70}$ The presence of the different observed phases suggests that the decoration process could involve partial reduction by nascent oxygen moieties, with possible reactions proceeding as follows:

$$
\begin{gathered}
\mathrm{Pr}^{3+} \rightarrow 3 \mathrm{Pr}^{4+}+\mathrm{Pr}^{3} \mathrm{OH}_{x} \\
\underset{\mathrm{S}}{\mathrm{KMnO}_{4} \rightarrow \mathrm{K}^{+}+\mathrm{MnO}_{4}{ }^{-}} \\
\mathrm{G} \rightarrow \mathrm{C}=\mathrm{O}+\mathrm{O}_{x}{ }^{x-} \stackrel{\mathrm{K}_{2} \mathrm{CO}_{3}}{\longrightarrow} \mathrm{G}+\mathrm{CO}_{2} \\
\mathrm{G} \rightarrow \mathrm{C}-\mathrm{O}+\mathrm{O}_{x}{ }^{x-} \rightarrow \mathrm{G}-\mathrm{C}=\mathrm{O}
\end{gathered}
$$

$\mathrm{KMnO}_{4}$ dissociation leads to $\mathrm{K}^{+}$cations and $\mathrm{MnO}_{4}{ }^{-}$anions: the cations co-ordinate with GO carbonyl groups to form carbonates. The carbonate nascent oxygen eliminates carbonyl groups as carbon dioxide, leaving defects on the GO surface, indicating reduced graphene oxide.

\subsection{Molecular and microstructural characterization}

Infrared spectra of GO and GO-Pr samples are shown in Fig. 8. The wide band at $3500 \mathrm{~cm}^{-1}$ is due to $\mathrm{O}-\mathrm{H}$ stretching of adsorbed water, and the small peaks at $c a .2800 \mathrm{~cm}^{-1}$ are attributed to alkyl stretching. The GO spectrum displays characteristic bands at $1740 \mathrm{~cm}^{-1}$ (carboxyl groups), $1630 \mathrm{~cm}^{-1}$ (aromatic $\mathrm{C}=\mathrm{C}$ ), and $1570 \mathrm{~cm}^{-1}(\mathrm{C}=\mathrm{O}$ in phenols), as well as hydroxyl and epoxy bands below $1500 \mathrm{~cm}^{-1} \cdot{ }^{71-74}$ On the other hand, the GO-Pr spectrum displays $\mathrm{GO}, \mathrm{C}=\mathrm{C}$ and hydroxyl bands related to the GO matrix, and new bands at 1300- 


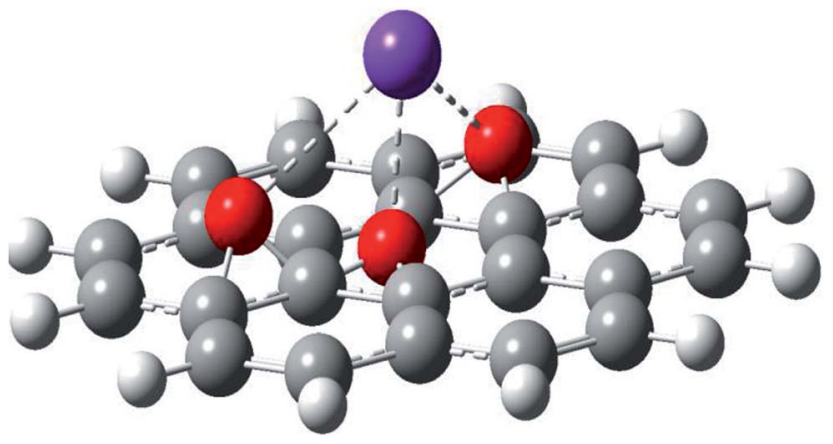

Fig. 7 The proposed reduction mechanism for GO.

$1500 \mathrm{~cm}^{-1}$ and $1041 \mathrm{~cm}^{-1}$, attributed to carbonates, are observed, as well as another peak at around $550 \mathrm{~cm}^{-1}$ related to Pr-O bonding. ${ }^{75}$ The FTIR results are consistent with the phases observed from XRD studies.

Raman spectra of GO and Pr + GO samples are presented in Fig. 10. D, G and $2 \mathrm{D}$ bands attributed to $\mathrm{sp}^{3}$ and carbon-vacancy defects in the graphitic structure, $\mathrm{sp}^{2}$ carbon symmetric vibrations, and high order vibrations of the carbon skeleton, respectively, are observed in both spectra. Evident reduction due to hydride anions is shown in the proposed mechanism in Fig. $9{ }^{76}$ related to the reduction degree of subjacent GO sheets upon Pr nanoparticle incorporation. The inset in Fig. 10 presents deconvolution of the spectra with regards to the D and $G$ peaks, as well as secondary $\mathrm{G}^{\prime}$ and $\mathrm{D}^{\prime}$ bands related to structural defects in the crystalline regions. The $A_{\mathrm{D}} / A_{\mathrm{G}}$ ratios were calculated to determine the relative crystalline ordering of the GO sample; $A_{\mathrm{D}} / A_{\mathrm{G}}$ is 1.42 for GO and 1.03 for GO-Pr respectively, which accounts for the higher degree of crystallinity in the graphitic structure of the GO-Pr sample. ${ }^{77}$

\subsection{Thermal, optical and hydrodynamic characterization}

The thermal studies were conducted under an inert atmosphere to confirm the praseodymium oxide stable decomposition temperature. GO and GO-Pr thermal decomposition data are

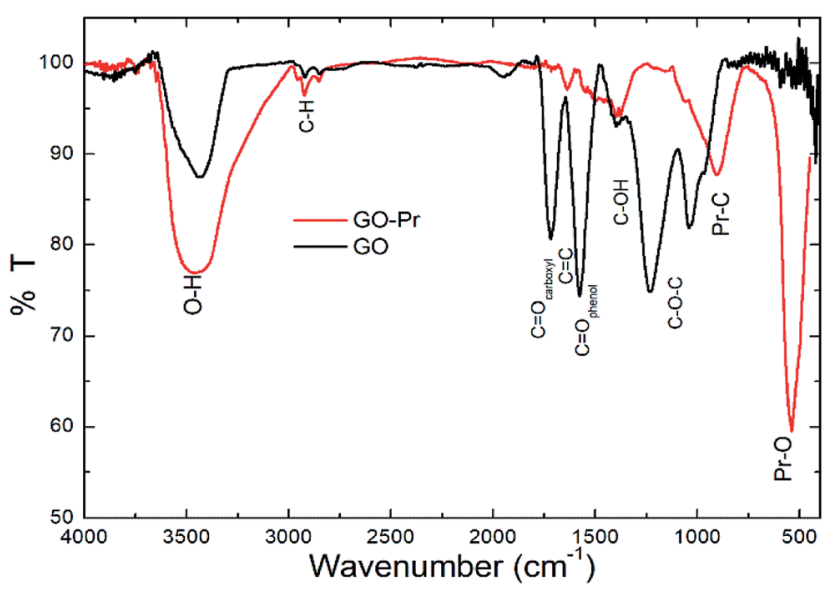

Fig. 8 FTIR spectra of GO and GO-Pr samples.
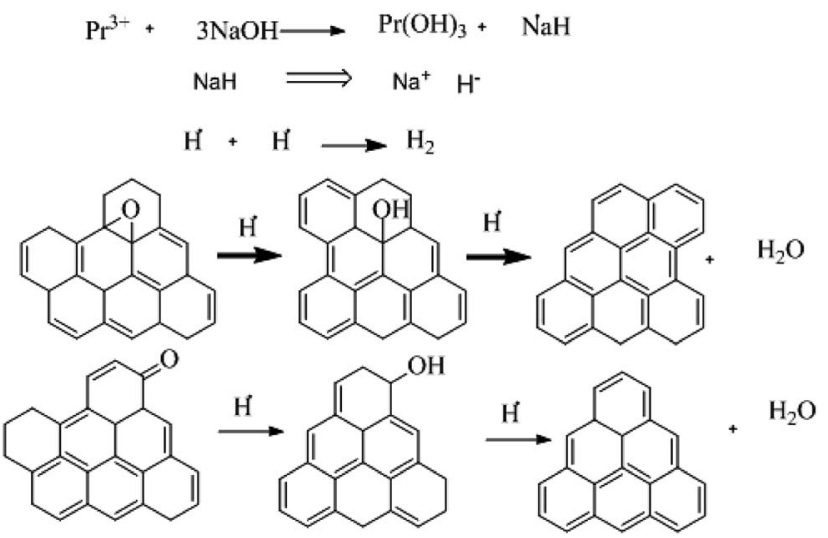

Fig. 9 The proposed mechanism for GO reduction.

shown in Fig. 11, measured as relative weight loss percentages. The initial weight loss at $200{ }^{\circ} \mathrm{C}$ (ref. 78) is due to water moisture in the GO sheets. This weight loss in GO is shown to be $50 \%$, and it constantly increases up to $500{ }^{\circ} \mathrm{C}$. This is attributed to carboxylate and carbonyl group decomposition. The further stability of GO is due to the presence of strong $\mathrm{sp}^{2}$ carbon conjugated bonds, up to $600{ }^{\circ} \mathrm{C} .{ }^{79}$ On the other hand, Pr + GO sheet weight loss was initiated at $350{ }^{\circ} \mathrm{C}$, with gradual weight loss up to $450{ }^{\circ} \mathrm{C}$; it is suggested that thermal decomposition of Pr oxide species suggests that $\mathrm{Pr}_{2}\left(\mathrm{CO}_{3}\right)_{3} \cdot x \mathrm{H}_{2} \mathrm{O}$ decomposition is the most probable feature observed in Fig. 11. For GO, the maximum decomposition rate occurs at $425{ }^{\circ} \mathrm{C}$, while that of GO-Pr shifts to $444^{\circ} \mathrm{C}$; as mentioned before, GO-Pr is thermally more stable because of the refractory nature of Pr oxides, which are formed at a temperature of $480{ }^{\circ} \mathrm{C}^{\mathbf{8 0}}$ Optical absorption spectra of GO and GO-Pr solutions are shown in Fig. 12. High absorbance and the typical $\pi$ to $\pi^{*}$ transition is observed at $230 \mathrm{~nm}$ in the GO suspension, as well as an abrupt decrease in absorbance at around $250 \mathrm{~nm}$, due to partial GO reduction. ${ }^{81}$ Correspondingly, the GO-Pr suspension absorption increases as the concentration increases. GO + Pr absorbance peaks from

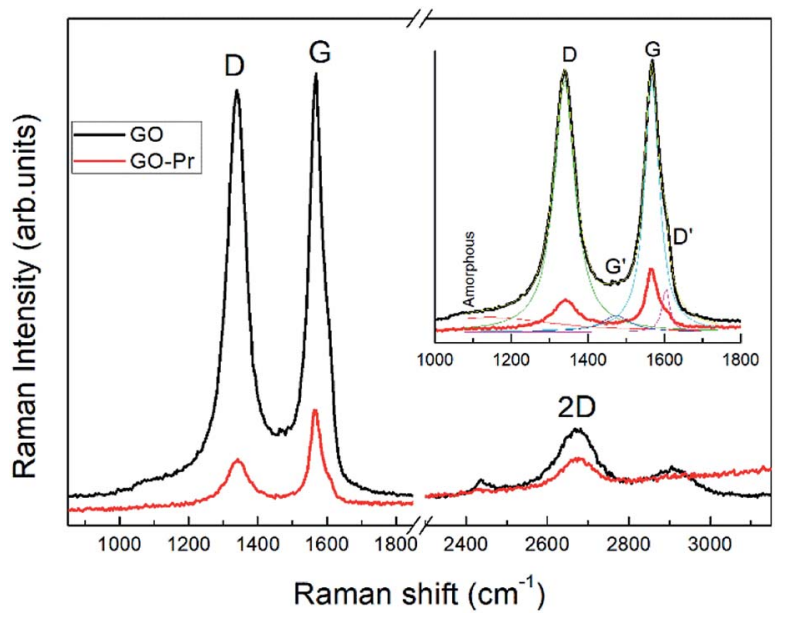

Fig. 10 Raman spectra of GO and GO-Pr samples showing spectral deconvolution to identify peaks. 


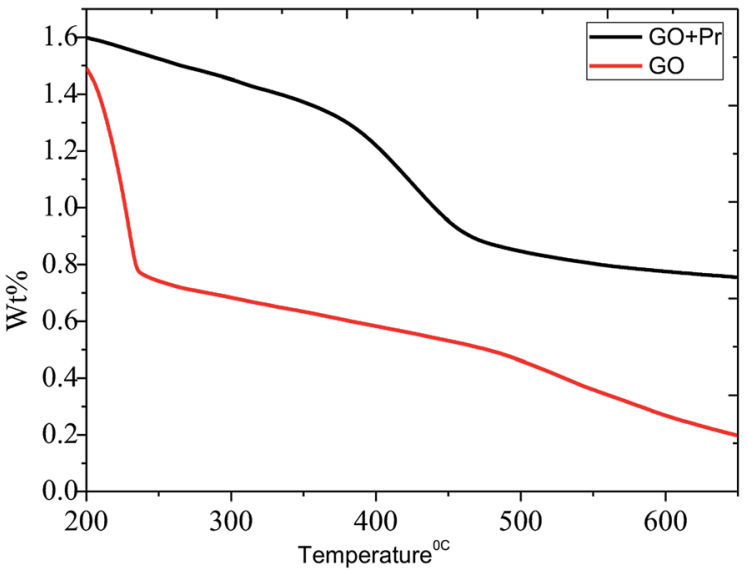

Fig. 11 TGA analyses of $\mathrm{GO}$ and $\mathrm{GO}+\mathrm{Pr}$.

$300 \mathrm{~nm}$ to $450 \mathrm{~nm}$, and at $470 \mathrm{~nm}$ are closely related to those reported for $\mathrm{Pr}_{6} \mathrm{O}_{11} \cdot{ }^{\mathbf{8 2 , 8 3}}$

Hydrodynamic light scattering techniques (DLS) have been used to study the hydrodynamic particle sizes of GO + Pr and GO samples, as shown in Fig. 13. The size distribution of the GO sample has a bimodal shape, with one maximum centred at $500 \mathrm{~nm}$ with a maximum frequency of $10 \%$, and the other one centred at $100 \mathrm{~nm}$ with a maximum of $70 \%$. This behaviour suggests agglomeration between the GO sheets, mostly due to hydrogen bonding within adjacent sheets. ${ }^{\mathbf{8 4}}$ Correspondingly, the GO-Pr sample has three maxima in its size distribution at $40 \mathrm{~nm}, 100 \mathrm{~nm}$ and $200 \mathrm{~nm}$. The smallest sizes would correspond to $\mathrm{Pr}^{3+}$ adhered nanoparticles, as imaged in the HRTEM micrographs, while the $100 \mathrm{~nm}$ and $200 \mathrm{~nm}$ maxima would correspond to Pr-decorated sheets and agglomerated sheets, respectively. ${ }^{85}$

The colloid mobility increases with Pr incorporation, as well as the surface charge, because Pr GO sheet decoration produced smaller agglomerates on one side and more exfoliated sheets on the other, as described before. On the other hand, the $\mathrm{Z}$

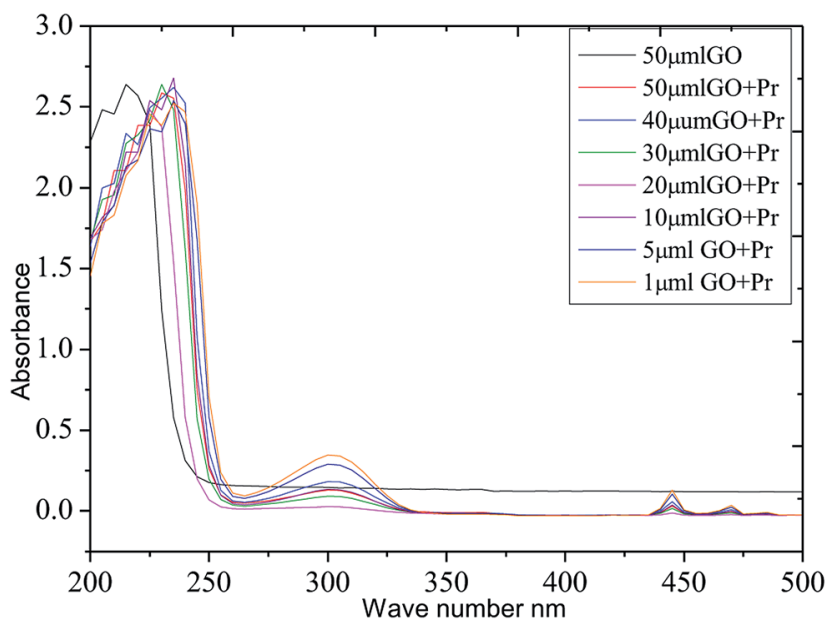

Fig. 12 UV-vis absorbance spectra of GO and GO + Pr suspensions.
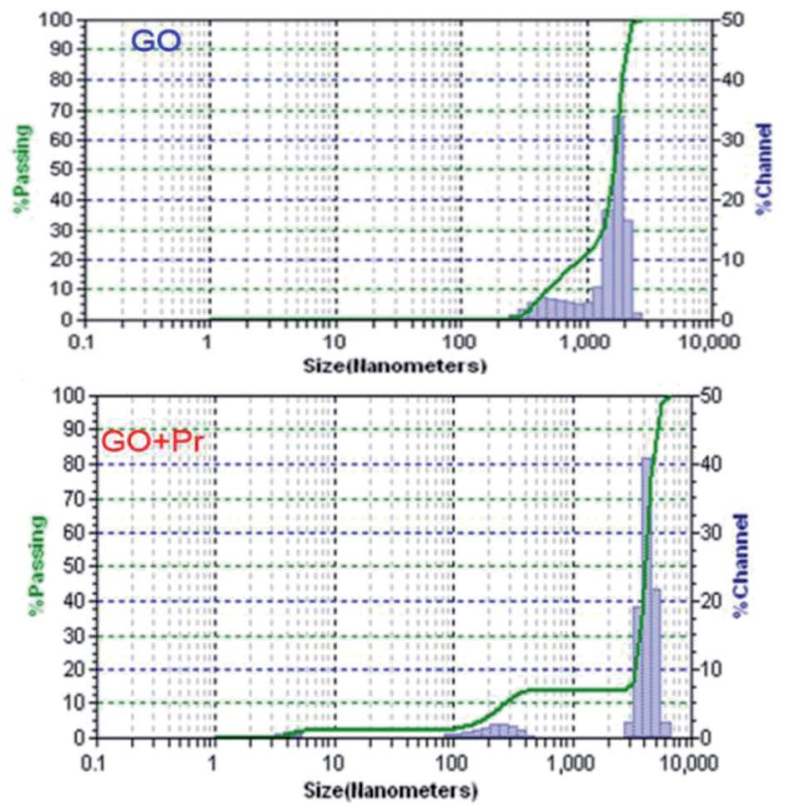

Fig. 13 Zeta potential data for GO and GO + Pr.

potential and conductivity are reduced upon decoration, due to disruption of the aromaticity within the graphene oxide basal sheet. The positive charge is related to GO reduction (Table 1).

\subsection{Ellipsometry studies}

The epoxy and GO + Pr coating thicknesses are shown in Fig. 14. The solid lines are from experimental data and the dotted lines are from model fitting. ${ }^{86} \mathrm{~A} \chi^{2}$ value of less than 5 is attributed to a close fit between model and experimental results. Our fitting results are less than 5, suggesting that the epoxy coating and GO + Pr coating are uniform, and the coating thickness $\chi^{2}$ values are shown in Table 2. The epoxy coating and GO + Pr coating are uniformly coated on the $\mathrm{Mg}$ alloy surfaces. ${ }^{87}$

\subsection{Electrochemical characterization}

Epoxy and GO + Pr coated magnesium (Mg) alloys were continuously immersed for 3 days in $1 \mathrm{M} \mathrm{H}_{2} \mathrm{SO}_{4}$ solution. Afterwards, potentiodynamic polarization test were carried out, as shown in Fig. 15. The epoxy coated $\mathrm{Mg}$ alloy corrosion current increased and the corrosion potential values decreased. This indicates that the epoxy coating showed poor physisorption and chemisorption on $\mathrm{Mg}$ alloys in the acidic medium, and the $\mathrm{Mg}$ alloy initiated cathodic hydrogen evolution ${ }^{88-90}$ and anodic alloy dissolution. In the case of the $\mathrm{GO}+\mathrm{Pr}$ composite coated $\mathrm{Mg}$ alloy, the corrosion current decreased and the corrosion

Table 1 A summary of the Z-potential data

\begin{tabular}{lcclll}
\hline S. no. & Mobility & Z & Charge & Polarity & $\sigma$ \\
\hline GO & 1.92 & 24.55 & 0.272 & + & 37 \\
GO-Pr & 11.10 & 14.90 & 0.414 & + & 26
\end{tabular}



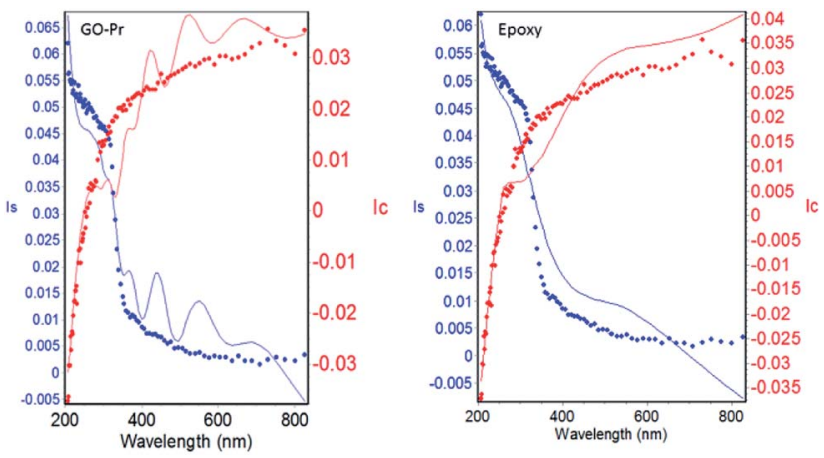

Fig. 14 GO + Pr coating and epoxy coating model and experimental data.

Table 2 Coating layer thickness values

\begin{tabular}{llc}
\hline Sample & $\chi^{2}$ fitting model & $\AA$ A coating thickness \\
\hline Epoxy & 0.293564 & 1026.7331 \\
GO & 0.254214 & 733.9902
\end{tabular}

potential increased due to strong physisorption and chemisorption. The potentiodynamic values are shown in Table 3 . Further, GO + Pr coated Mg alloy hydrogen evolution and anodic alloy dissolution were controlled by the GO + Pr composite coating in the acidic medium.

EIS spectra of epoxy and GO + Pr coated Mg alloys are presented in Fig. 16A; the Nyquist spectra indicates that the epoxy coated $\mathrm{Mg}$ alloy semicircle is suppressed, and this is attributed to pitting corrosion on the surface following attack by $\mathrm{Cl}$ ions. Hence, as shown in Fig. 16B and C, the epoxy coating Bode and frequency plots are also suppressed, due to localised corrosion initiated on the alloy surface due to epoxy coating failure in the

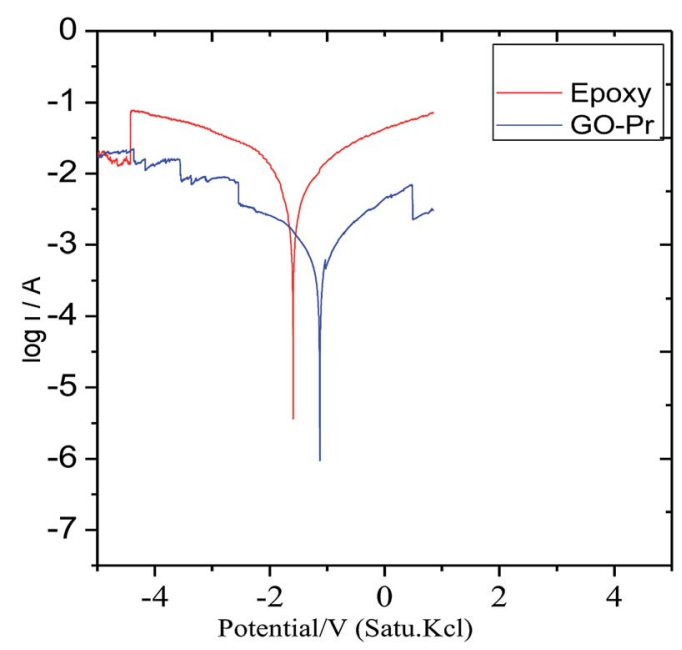

Fig. 15 The potentiodynamic polarization of the coated $\mathrm{Mg}$ alloys after 3 days of immersion in $1 \mathrm{M} \mathrm{H}_{2} \mathrm{SO}_{4}$.
Table 3 Magnesium alloy potentiodynamic and impedance values after 3 days of immersion in $1 \mathrm{M} \mathrm{H}_{2} \mathrm{SO}_{4}$

\begin{tabular}{llllll}
\hline Sample & $-E_{\text {corr }} \mathrm{mV}$ & $-I_{\text {corr }} \mathrm{mA}$ & $\eta_{\mathrm{IE}} \%$ & $R_{\mathrm{ct}} \Omega$ & $C_{\mathrm{dl}} \mu \mathrm{F}$ \\
\hline Epoxy & 1.13 & 3.540 & - & 489 & 6.58 \\
E + GO-Pr & 1.60 & 1.978 & 72.3 & 890 & 2.52 \\
\hline
\end{tabular}

acidic medium. On the other hand, charge transfer is decreased, and the double layer capacitance value is increased due to the poor physisorption of the epoxy coating on the alloy surface. This is attributed to the epoxy coating not being suitable as a long term coating material in acidic media. In the case of the GO + Pr coated Mg alloy, the Nyquist semicircle increased and the Bode and frequency plots are also increased due to the strong physisorption of the $\mathrm{GO}+\mathrm{Pr}$ composite on the $\mathrm{Mg}$ alloy. Further, the charge transfer resistance $R_{\mathrm{ct}}$ value is increased and the double layer capacitance value is decreased due to $\mathrm{GO}+\mathrm{Pr}$ chemisorption on the alloy surface and the uniform surface. ${ }^{91-93}$ The charge transfer resistance and double layer capacitance values are shown in Table 3. Furthermore, the GO + Pr composite material shows excellent anticorrosion resistance in acidic environments due the Pr nanoparticle diffusing to the basal plane of the GO internal layer; this enhances passivation on the $\mathrm{Mg}$ alloy surface and controls $\mathrm{H}_{2}$ evolution. In the presented research, in decorated GO + Pr, the Pr nanoparticles provide synergetic effects due to their sub-nanometre size, and graphene oxide should act as diffusion barrier layer. Decorated GO-Pr, with sizes of around $200 \mathrm{~nm}$, would provide mixed barrier inhibition, while free nonbonding electrons in Pr-GO sheet functional groups interacting with the alloy surface would act directly as inhibitors of hydrogen evolution Fig. 17 shows the equivalent circuit for fitting the electrochemical impedance values. The fitting values are presented in Table 3.

\subsection{Surface protection studies using the magnesium alloy AZ31}

Fig. 18A shows an FESEM micrograph before the coating of the $\mathrm{Mg}$ alloy. Fig. 18B shows the epoxy coated $\mathrm{Mg}$ alloy after 3 days of immersion in $1 \mathrm{M} \mathrm{H}_{2} \mathrm{SO}_{4}$ medium, and Fig. 18C shows EDX data from the epoxy coated $\mathrm{Mg}$ alloy. These results indicate that the epoxy coating is not stable in an acidic environment. Further, at the epoxy coated $\mathrm{Mg}$ alloy grain boundary, localised corrosion is initiated on the alloy surface due to hydrogen evolution. ${ }^{\mathbf{9 4 , 9 5}}$ In the case of the GO + Pr composite coated $\mathrm{Mg}$ alloy, results after 3 days of immersion in $1 \mathrm{M} \mathrm{H}_{2} \mathrm{SO}_{4}$ are presented in Fig. 18D-F. Here, the $\mathrm{Mg}$ alloy surface is homogenous and, at the grain boundary, pitting corrosion does not appear on the alloy surface. This is attributed to the $\mathrm{Pr}+\mathrm{GO}$ coating showing strong physisorption on the alloy surface. ${ }^{\mathbf{9 6 9}}$ According to the EDX results relating to the composition of the epoxy coated $\mathrm{Mg}$ alloy, the $\mathrm{Zn}$ element dissolved in the aggressive medium. In the case of the $\mathrm{Pr}+\mathrm{GO}$ coated $\mathrm{Mg}$ alloy, the composition of elements is not changed due to the strong 

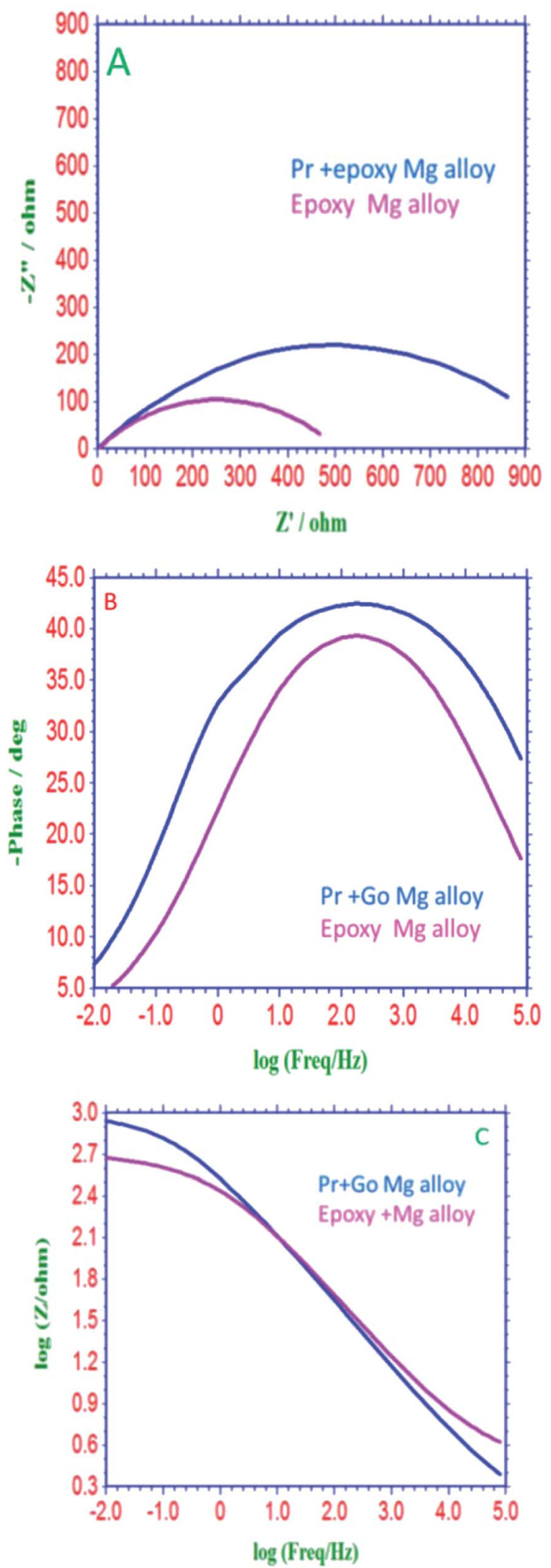

Fig. 16 (A) Nyquist, (B) Bode and (C) frequency plots of $\mathrm{Mg}$ alloys coated with epoxy and $\mathrm{GO}+\mathrm{Pr}$, after 3 days of immersion in $1 \mathrm{M}$ $\mathrm{H}_{2} \mathrm{SO}_{4}$ medium.

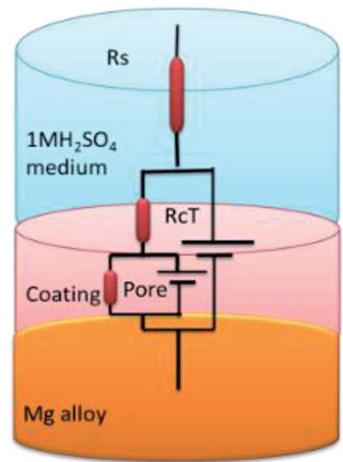

Fig. 17 The equivalent circuit.
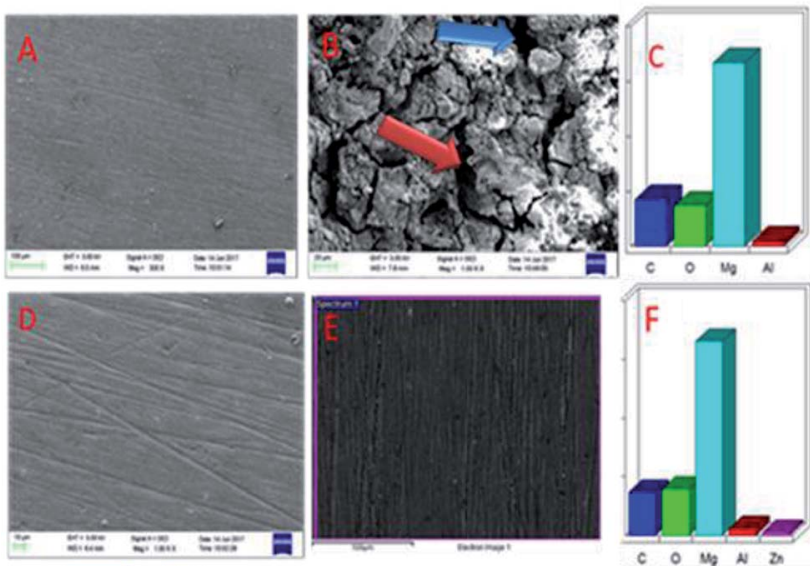

$\Longrightarrow$ Pitting corrosion

$\Longrightarrow$ Intergranular corrosion

Fig. 18 SEM micrographs of the epoxy coated AZ31 alloy (A) before immersion and (B) after immersion in the acidic medium, and (C) EDX data. (D), (E), and (F) shows corresponding data for the GO + Pr coated alloy.

physisorption of the Pr + GO material. Furthermore, FESEM element mapping results suggesting that, from the element composition, $\mathrm{Zn}$ dissolution is high in the epoxy coated $\mathrm{Mg}$ alloy, compared with the $\mathrm{Pr}+\mathrm{GO} \mathrm{Mg}$ alloy, are presented in Fig. 19. Further, the Pr + GO composite coated $\mathrm{Mg}$ alloy element composition, showing uniform distribution, is presented in Fig. 20. From the microstructural results, it is suggested that Pr + GO shows strong physisorption and chemisorption compared with the epoxy coating. The GO + Pr composite coating is significantly corrosion resistant in acidic environments.

The $\mathrm{Mg}$ alloy microstructural results suggest that the $\mathrm{Pr}+\mathrm{GO}$ coating exhibits excellent corrosion resistance compared with the epoxy coating on the $\mathrm{Mg}$ alloy in the acidic medium.

3.6.1 Quantum chemical graphene oxide model and functional groups. According to a literature reported model, ${ }^{98}$ we have investigated 30 atom graphene oxide models and their functional groups for possible electron donation and accepting involving the alloy and the surface, as shown in Fig. 21. The highest occupied molecular orbital (HOMO) values are assigned 

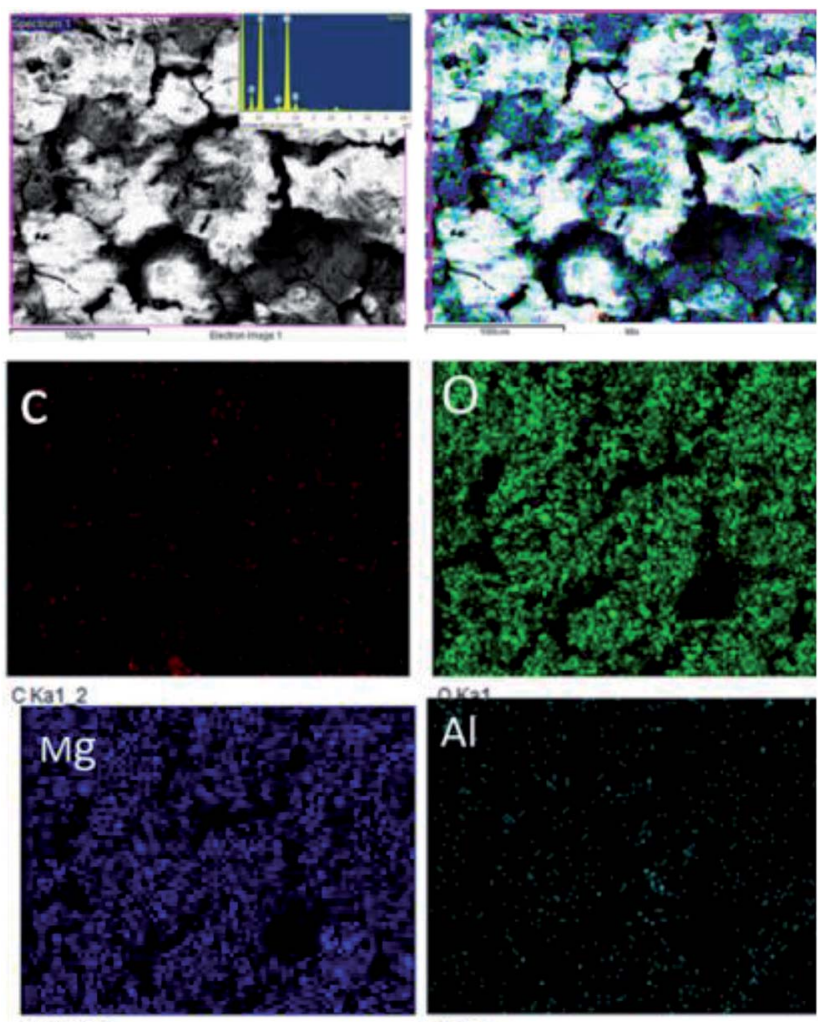

MoKa1_2

A Ka1

Fig. 19 Elemental mapping of the epoxy coated Mg alloy.
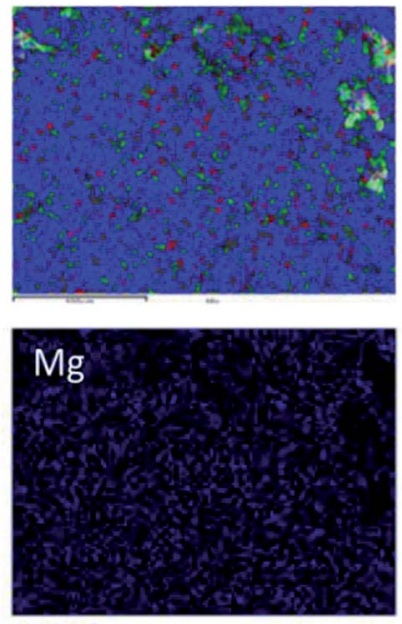

Mg Ka1_2

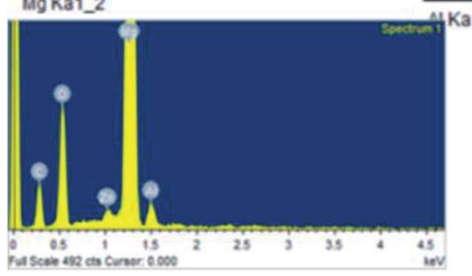

Fig. 20 Elemental mapping of the GO + Pr coated Mg alloy.

for electron donation to the vacant d-orbital of the alloy. The lowest unoccupied molecular orbital (LUMO) accepts electrons from the alloy surface. The model quantum chemical values are

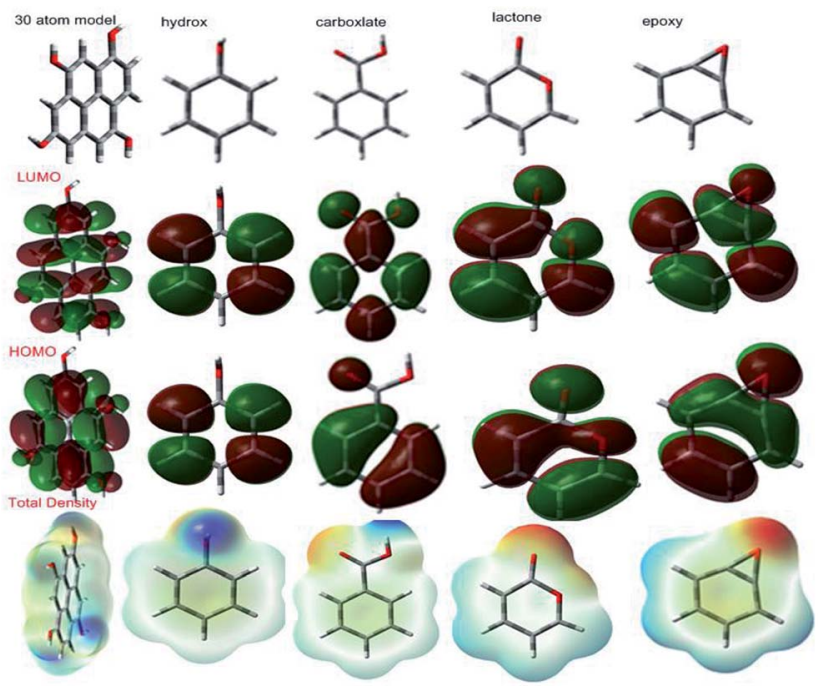

Fig. 21 GO functional group HOMO and LUMO levels.

favourable for electron accepting and donating capabilities. The GO model global softness value increased; this indicates that graphene oxide could be adsorbed on the alloy surface. The global hardness value also decreased; this indicates that with graphene oxide functional groups, lone pair electrons tend to give partially filled vacant $\mathrm{d}$ orbitals in $\mathrm{Mg}$ alloys. Another parameter, dipole movement, is a significant factor for inhibitor molecules to increase the reactivity. The GO functional group dipole movements are gradually increased; this leads to increased adsorption on $\mathrm{Mg}$ alloy surfaces. Further, the total density values also support enhanced adsorption on the alloy surface. Hence, the GO sheet negative charge could repel electrolytes and water molecules from the alloy surface. The total density value gradually increases; this leads to protecting the surface from corrosive ion attacks. The quantum chemical 30 atom GO model and functional group results are in good agreement with the experimental results (Table 4).

3.6.2 The possible mechanism. The 30 atom model of the graphene oxide sheet total density and the sulphate ion repulsion model are presented in Fig. 22. Graphene oxide has been studied as an excellent impermeable barrier layer on iron

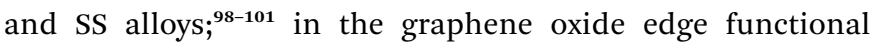
groups, such as carbonyl, hydroxyl and carboxylate, free electrons increase the chemisorption on the alloy surface. This attributed negative charge on the graphene oxide could repel electrolyte ions. Further, the quantum chemical calculation values, such as global softness and hardness, HOMO and LUMO levels, and electrophility, are favourable for electron donation and accepting from the vacant d orbitals of the alloy. These results indicate that $\mathrm{Pr}+\mathrm{GO}$ sheets are strongly adsorbed on the alloy surface. For that reason, the Pr-graphene oxide composite coating acts as an impermeable barrier layer. In the case of epoxy coatings, electrolytes can easily move through micropores towards the coating, initiating localised corrosion on the alloy surface. 
Table 4 Quantum chemical GO functional group values

\begin{tabular}{|c|c|c|c|c|c|c|c|c|}
\hline S. No & $-\mathrm{HOMO}$ eV & -LUMO eV & $\eta$ & $\chi$ & $\omega$ & $\sigma$ & D.M $(\mu)$ & T.D \\
\hline Model & 6.9644 & 2.1320 & 2.4162 & 7.4240 & 3.7119 & 0.4138 & 2.3010 & 906.1210 \\
\hline Hydroxy & 6.5454 & 0.0054 & 3.2700 & 0.0176 & 0.0084 & 0.3058 & 1.7610 & 305.7674 \\
\hline Epoxy & 6.0801 & 0.3044 & 2.8878 & 0.9253 & 0.4626 & 0.3462 & 2.4099 & 304.4123 \\
\hline Ketone & 6.1260 & 0.2163 & 5.9009 & 0.6625 & 0.3306 & 0.1694 & 2.8162 & 308.1669 \\
\hline Lactone & 6.5130 & 1.6775 & 2.4177 & 5.4627 & 2.7313 & 0.4136 & 4.4600 & 341.4320 \\
\hline Carboxylate & 7.1685 & 1.2536 & 2.9574 & 4.4932 & 2.2465 & 0.3381 & 1.6361 & 418.5017 \\
\hline
\end{tabular}

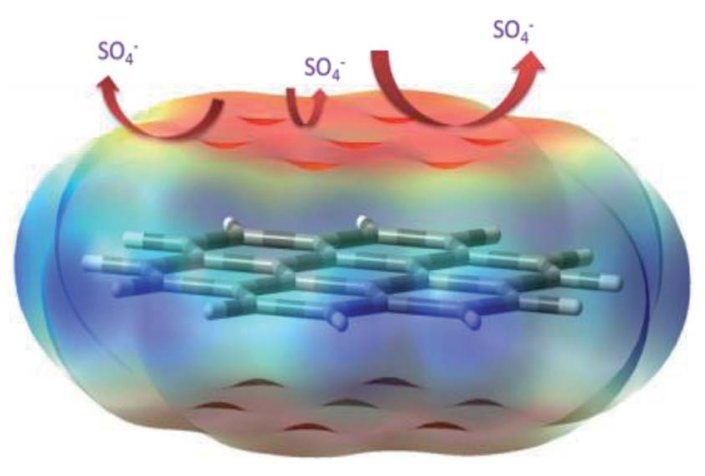

Fig. 22 A proposed scheme for the repulsion of corrosive ions.

\section{Conclusions}

Praseodymium decorated graphene oxide was prepared and tested for corrosion inhibition with $\mathrm{Mg}$ alloys. The praseodymium decorated graphene oxide coated AZ31 Mg alloy was immersed for 3 days in $1 \mathrm{M} \mathrm{H}_{2} \mathrm{SO}_{4}$. The results indicates that GO is partially reduced upon Pr-decoration and Pr carbonates and oxides are present, as well as some metallic Pr due to the disproportionation of $\mathrm{Pr}^{3+}$. Strongly adhered nanoparticles were observed via HRTEM and measured using DLS, where events related to decorated and agglomerated sheets were also recorded. From TGA analysis, it was found that decorated graphene oxide is thermally more stable than pristine GO. The $\mathrm{Pr}+\mathrm{GO}$ composite coating was a significant barrier in acidic media compared to the epoxy coating, which was confirmed via electrochemical and microscopy methods. The GO + Pr composite coating corrosion potential is increased compared with the epoxy coating. And GO 30 atom model DFT study results suggest that electron accepting and donation occurs from the alloy surface. The experimental values and theoretical data suggest that the GO + Pr coating shows higher corrosion resistance in acidic media.

\section{Conflicts of interest}

The authors herein declare no conflicts of interest.

\section{Acknowledgements}

NP acknowledges the Central University of Gujarat Central Instrument facility, the UGC Network Resource Centre Hyderabad/University of Hyderabad, and a Non-Net fellowship, as well as Prof M. Sathiyendiran for support regarding the completion of this work. The authors thank Dr A. Srinivasan at the Materials Science and Technology Division CSIR-National Institute for Interdisciplinary Science and Technology (CSIRNIIST) in Thiruvananthapuram for providing the AZ31 Mg alloy; this work was partially financed by SIP-IPN Project 20161804.

\section{References}

1 P. D. Ducharme and J. Mauzeroll, Anal. Chem., 2015, 87, 7499-7509.

2 R. L. Liu, J. R. Scully, G. Williams and N. Birbilis, Electrochim. Acta, 2018, 260, 184-195.

3 (a) S. Thomas, N. Birbilis, M. S. Venkatraman and I. S. Cole, Corros. Sci., 2013, 69, 11-22; (b) V. Chakarova, Tz. Boiadjieva-Scherzer, D. Kovacheva, H. Kronberger and M. Monev, Corros. Sci., 2018, 140, 73-78; (c) S. Dea and J. L. Lutkenhaus, Green Chem., 2018, 20, 506.

4 A. Frignani, V. Grassi, F. Zanotto and F. Zucchi, Corros. Sci., 2012, 63, 29-39.

5 D. Buggio, M. Trueba and S. P. Trasatti, Corros. Sci., 2016, 104, 173-186.

6 X. Guo, K. Du, Q. Guo, Y. Wang, R. Wang and F. Wang, Corros. Sci., 2013, 76, 129-141.

7 N. H. Helal and W. A. Badawy, Electrochim. Acta, 2011, 56, 6581-6587.

8 J. Hu, D. Huang, G. L. Song and X. Guo, Corros. Sci., 2011, 53, 4093-4101.

9 J. Hu, D. Huang, G. Zhang, G. L. Song and X. Guo, Corros. Sci., 2012, 63, 367-378.

$10 \mathrm{~J}$. Hu, D. Zeng, Z. Zhang, T. Shi, G. L. Song and X. Guo, Corros. Sci., 2013, 74, 35-43.

11 D. Huang, J. Hu, G. L. Song and X. Guo, Electrochim. Acta, 2011, 56, 10166-10178.

12 J. Xu, Q. Yang, M. S. Javed, Y. Gong, K. Aslama and C. Chen, RSC Adv., 2017, 7, 5880.

13 X.-B. Chen, N. Birbilis and T. B. Abbott, Corros. Sci., 2012, 55, 226-232.

14 X.-B. Chen, N. Birbilis and T. B. Abbott, Corros. Sci., 2011, 53, 2263-2268.

15 G. Williams, H. N. McMurray and R. Grace, Electrochim. Acta, 2010, 55, 7824-7833.

16 N. T. Kirkland, G. Williams and N. Birbilis, Corros. Sci., 2013, 77, 407-409.

17 N. T. Kirkland, G. Williams and N. Birbilis, Corros. Sci., 2012, 65, 5-9. 
18 G. Williams, H. L. Dafydd and R. Grace, Electrochim. Acta, 2013, 109, 489-501.

19 G. Williams, N. Birbilis and H. Neil McMurray, Faraday Discuss., 2015, 180, 313-330.

20 D. S. Gandel, M. A. Easton, M. A. Gibson, T. Abbott and N. Birbilis, Corros. Sci., 2014, 81, 27-35.

21 D. Eaves, G. Williams and H. N. McMurray, Electrochim. Acta, 2012, 79, 1-7.

22 G. Williams, H. L. Dafydd, H. N. McMurray and N. Birbilis, Electrochim. Acta, 2016, 219, 401-411.

23 R. L. Liu, Z. R. Zeng, J. R. Scully, G. Williams and N. Birbilis, Corros. Sci., 2018, 140, 18-29.

24 Y. Wang, R. K. Gupta, N. L. Sukiman, R. Zhang, H. J. Davies and N. Birbilis, Corros. Sci., 2013, 73, 181-187.

25 A. Samaniego, K. Gusieva, I. Llorente, S. Feliu and N. Birbilis, Corros. Sci., 2014, 89, 101-110.

26 Y. Qiao, W. Li, G. Wan and X. Zhang, J. Rare Earths, 2015, 33, 647-654.

27 S. Li, W. Zheng, B. Tang, D. Zeng and X. Guo, J. Rare Earths, 2007, 25, 227-232.

28 Z. Weichao, L. Shuangshou, T. Bin, Z. Daben and G. Xutao, J. Rare Earths, 2006, 24, 346-351.

29 G. bi, J. Jian, F. Zhang, D. Fang, Y. LI, Y. ma and Y. Hao, J. Rare Earths, 2016, 34, 931-937.

30 G. S. Frankel, A. Samaniego and N. Birbilis, Corros. Sci., 2013, 70, 104-111.

31 S. H. Salleh, S. Thomas, J. A. Yuwono, K. Venkatesan and N. Birbilis, Electrochim. Acta, 2015, 161, 144-152.

32 S. Fajardo, C. F. Glover, G. Williams and G. S. Frankel, Electrochim. Acta, 2016, 212, 510-521.

33 Y.-J. Wu, X.-B. Chen, G. Williams, J. R. Scully, T. Gengenbach and N. Birbilis, RSC Adv., 2016, 6, 4340843417.

34 J. Y. Chen, X. Chen, J.-L. Li, B. Tang, N. Birbilis and X. Wang, J. Mater. Chem. A, 2014, 2, 5738-5743.

35 N. T. Kirkland, T. Schiller, N. Medhekar and N. Birbilis, Corros. Sci., 2012, 56, 1-4.

36 Y. Zhu, J. Zhuang, Y. Yu and X. Zeng, J. Rare Earths, 2013, 31, 734-740.

37 E. Zhang, Y. Chen and Y. Tang, J. Rare Earths, 2012, 30, 269273.

38 G. Kong, L. Liu, J. Lu, C. Che and Z. Zhong, J. Rare Earths, 2010, 28, 461-465.

39 G. Kong, J. Lu and H. Wu, J. Rare Earths, 2009, 27, 164-168. 40 X. Xing, Z. Han, H. Wang and P. Lu, J. Rare Earths, 2015, 33, 1122-1128.

41 A. K. Mishra and R. Balasubramaniam, Corros. Sci., 2007, 49, 1027-1044.

42 A. L. Rudda, C. B. Breslin and F. Mansfield, Corros. Sci., 2000, 42, 275-288.

43 X. Li, S. Deng, H. Fu and G. Mu, Corros. Sci., 2008, 50, 35993609.

44 X. Li, S. Deng, H. Fu and G. Mu, Corros. Sci., 2009, 51, 26392651.

45 N. D. Nama, A. Somers, M. Matheshc, M. Seter, B. Hinton, M. Forsyth and M. Y. J. Tana, Corros. Sci., 2014, 45, 128-138.
46 M. Machkova, E. A. Matter, S. Kozhukharov and V. Kozhukharov, Corros. Sci., 2013, 69, 396-405.

47 A. E. Somers, B. R. W. Hinton, C. B. Dickason, G. B. Deacon,

P. C. Junk and M. Forsyth, Corros. Sci., 2018, 139, 430-437.

48 H. Zheng, M. Guo, Y. Shao, Y. Wang, B. Liu and G. Meng, Corros. Sci., 2018, 139, 1-12.

49 L. Yang, Y. Wan, Z. Qin, Q. Xu and Y. Min, Corros. Sci., 2018, 130, 85-94.

50 I. Wlasny, P. Dabrowski, M. Rogala, I. Pasternak, W. Strupinski, J. M. Baranowski and Z. Klusek, Corros. Sci., 2015, 92, 69-75.

51 C. F. Glover, C. A. J. Richards, G. Williams and H. N. McMurray, Corros. Sci., 2018, 136, 304-310.

52 C. F. Glover, C. Richards, J. Baker, G. Williams and H. N. McMurray, Corros. Sci., 2017, 114, 169-172.

53 J. Zhao, X. Xie and C. Zhang, Corros. Sci., 2017, 114, 146155.

54 S. Pourhashem, M. R. Vaezi, A. Rashidi and M. R. Bagherzadeh, Corros. Sci., 2017, 115, 78-92.

55 E. G. Yazdi, Z. S. Ghahfarokhia and M. Bagherzadeh, New J. Chem., 2017, 41, 12470-12480.

56 S. Mayavan, T. Siva and S. Sathiyanarayanan, RSC Adv., 2013, 3, 24868-24871.

57 A. Madhan Kumar, R. Suresh Babu, I. B. Obot and Z. M. Gasem, RSC Adv., 2015, 5, 19264-19272.

58 C. Liu, S. Qiu, P. Du, H. Zhao and L. Wang, Nanoscale, 2018, 10, 8115-8124.

59 R. K. Gupta, M. Malviya, C. Varma and M. A. Quraishi, Mater. Chem. Phys., 2017, 198, 360-373.

60 M. J. Nine, M. A. Cole, D. N. H. Tran and D. Losic, J. Mater. Chem. A, 2015, 3, 12580-12602.

61 D. Ponnamma, K. K. Sadasivuni, M. Strankowski, P. Moldenaers, S. Thomas and Y. Grohens, RSC Adv., 2013, 3, 16068-16079.

62 J. Jayaraj, S. Amruth Raj, A. Srinivasan, S. Ananthakumar, U. T. S. Pillai, N. G. K. Dhaipule and U. KamachiMudali, Corros. Sci., 2016, 113, 104-115.

63 W. Sun, L. Wang, T. Wu, Y. Pan and G. Liu, J. Mater. Chem. A, 2015, 3, 16843-16848.

64 R. K. Gupta, M. Malviya, C. Verma, N. K. Gupta and M. A. Quraishi, RSC Adv., 2017, 7, 39063.

65 A. Kumar, R. Anant, K. 1 Kumar, S. S. Chauhan, S. Kumar and R. Kumara, RSC Adv., 2016, 6, 113405.

66 (a) J. C. Soares, K. P. F. Siqueira, P. C. de Sousa Filho, R. L. Moreira and A. Dias, Dalton Trans., 2017, 46, 825835; (b) Q. Xu, M. Zeng, Z. Feng, D. Yin, Y. Huang, Y. Chen, C. Yan, R. Li and G. U. Yi, RSC Adv., 2016, 6, 31484-31496.

67 (a) N. Ahmad, M. M. Ahmad and P. N. Kotru, RSC Adv., 2015, 5, 93808-93817; (b) Y. Borchert, P. Sonstro, M. Wilhelm, H. Borchert and M. Baumer, J. Phys. Chem. C, 2008, 112, 3054-3063.

68 H. Al Kutubi, L. Rassaei, W. Olthuis, G. W. Nelson, J. S. Foord, P. Holdway, M. Carta, R. Malpass-Evans, N. B. McKeown, S. C. Tsang, R. Castaing, T. R. Forder, M. D. Jones, D. He and F. Marken, RSC Adv., 2015, 5, 73323-73326. 
69 Y. Guan, T. Tsuboi, Y. Huang and W. Huang, Dalton Trans., 2014, 43, 3698-3703.

70 (a) M. A. Gusowski, H. C. Swart, L. S. Karlsson and M. T. Gusowska, Nanoscale, 2012, 4, 541-546; (b) G. A. M. Hussein, J. Anal. Appl. Pyrolysis, 1994, 29, 89-102.

71 C. K. Chua and M. Pumera, Chem. Soc. Rev., 2014, 43, 291312.

72 M. Balaguer, C. Solís, S. Roitsch and J. M. Serra, Dalton Trans., 2014, 43, 4305-4312.

73 (a) J. M. C. Moreno, V. G. Pol, S. H. Suh and M. Popa, Inorg. Chem., 2010, 49, 10067-10073; (b) A. Dodd, J. Colloid Interface Sci., 2013, 392, 137-140.

74 S. Z. Ajabshir and M. S. Niasari, New J. Chem., 2015, 39, 3948-3955.

75 Y. A. El-Nadi, J. Rare Earths, 2010, 28, 215.

76 (a) M. A. Krishnan, K. S. Aneja, A. Shaikh, S. Bohm, K. Sarkar, H. L. Mallika Bohm and V. S. Raja, RSC Adv., 2018, 8, 499; (b) D. He, Z. Peng, W. Gong, Y. Luo, P. Zhao and L. Kong, RSC Adv., 2015, 5, 11966; (c) L. R. Radovic, A. Suarez, F. Burgos and J. O. Sofo, Carbon, 2011, 49, 4226-4238.

77 (a) V. H. Pham, H. D. Pham, T. T. Dang, S. H. Hur, E. J. Kim, B. S. Kong, S. Kima and J. S. Chung, J. Mater. Chem., 2012, 22, 10530-10536; (b) C. H. Lee, J. Yu, Y. Wang, A. Y. L. Tang, C. W. Kan and J. H. Xin, RSC Adv., 2018, 8, 16593.

78 (a) S. Z. Ajabshir, M. S. Niasari and M. Hamadanian, RSC $A d v .$, 2015, 5, 33792-33800; (b) X. Zhou, L. J. Broadbelt and R. Vinu, Adv. Chem. Eng., 2016, 49, 95-198.

79 L. Guangxiang, Z. Hong and R. Xiaoming, J. Rare Earths, 2011, 29, 1100.

80 (a) V. H. Pham, H. D. Pham, T. T. Dang, S. H. Hur, E. J. Kim, B. S. Kong, S. Kima and J. S. Chung, J. Mater. Chem., 2012, 22, 10530-10536; (b) B. M. A. Zied, Y. A. Mohamed and A. M. Asiri, J. Rare Earths, 2013, 31, 701.

81 A. Sarkar, C. Loho, L. Velasco, T. Thomas, S. S. Bhattacharya, H. Hahn and R. Djenadic, Dalton Trans., 2017, 46, 12167-12176.

82 (a) Y. Haibin, Z. Jianhui, Y. Ruijin and S. Qiang, J. Rare Earths, 2009, 27, 308; (b) B. S. Balachandran, K. Thirumalai and M. Swaminathan, RSC Adv., 2014, 4, 27642-27653.

83 (a) R. F. Gonzalez, B. J. anLopez and E. C. P. Escribano, J. Mater. Chem., 2011, 21, 497-504; (b) Y. Borchert,
P. Sonstrom, M. Wilhelm, H. Borchert and M. Baumer, J. Phys. Chem. C, 2008, 112, 3054-3063.

84 S. Stankovich, R. D. Piner, S. T. Nguyen and R. S. Ruoff, Carbon, 2006, 44, 3342-3347.

85 (a) C. Shih, S. Lin, R. Sharma, M. S. Strano and D. Blankschtein, Langmuir, 2012, 28, 235-241; (b) N. Hara, Y. Kobayashi, D. Kagaya and N. Akao, Corros. Sci., 2007, 49, 166-175.

86 N. Palaniappan, L. R. Chowhan, S. Jothi, I. G. Bosco and I. S. Cole, Surf. Interfaces, 2016, 000, 1-10.

87 P. W. Chu, E. L. Mire and E. A. Marquis, Corros. Sci., 2017, 128, 253-264.

88 J. Liao and M. Hotta, Corros. Sci., 2016, 112, 276-288.

89 F. Singer, M. Schlesak, C. Mebert, S. Hohn and S. Virtanen, ACS Appl. Mater. Interfaces, 2015, 26758-26766.

90 Q. Liu, D. Chen and Z. Kang, ACS Appl. Mater. Interfaces, 2015, 7, 1859-1867.

91 L. B. Tong, J. B. Zhang, C. Xu, X. Wang, S. Y. Song, Z. H. Jiang, S. Kamado, L. R. Cheng and H. J. Zhang, Carbon, 2016, 109, 340-351.

92 P. Porızka, I. Rocnakova, J. Klus, D. Prochazka, L. Sladkova, P. Sperka, Z. Spotz, L. Celko, K. Novotny and J. Kaiser, J. Anal. At. Spectrom., 2015, 30, 2099-2106.

93 P. W. Chu, E. L. Mire and E. A. Marquis, Corros. Sci., 2017, 128, 253-264.

94 H. Qi, Y. Qian, J. Xua, J. Zuo and M. L. Lia, Corros. Sci., 2018, 138, 170-177.

95 Z. Qiu, R. Wang, J. Wu, Y. Zhang, Y. Qu and X. Wu, RSC Adv., 2015, 5, 44149.

96 W. Shang, C. He, Y. Wen, Y. Wang and Z. Zhang, RSC Adv., 2016, 6, 113967-113980.

97 C. Zhang, D. M. Dabbs, L. M. Liu, I. A. Aksay, R. Car and A. Selloni, J. Phys. Chem. C, 2015, 119, 18167-18176.

98 Y. H. Yu, Y. Y. Lin, C. H. Lin, C. C. Chan and Y. C. Huang, Polym. Chem., 2014, 5, 535-550.

99 R. Kumar Gupta, M. Malviya, C. Verma, N. K. Gupta and M. A. Quraishi, RSC Adv., 2017, 7, 39063-39074.

100 A. Madhan Kumar, R. Suresh Babu, I. B. Obot and Z. M. Gasema, RSC Adv., 2015, 5, 19264-19272.

101 N. Palaniappan, L. Raju Chowhan, S. Jothi, I. G. Bosco and I. S. Cole, Surf. Interfaces, 2016, 000, 1-10. 